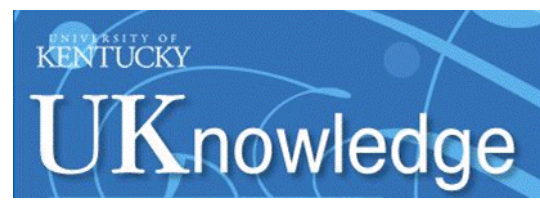

University of Kentucky

UKnowledge

6-19-2015

\title{
Quantitative Correlation of Rainfall and Earth Surface Displacements for Slope Stability Studies
}

Chrysanthos Steiakakis

General Consulting Ltd. ISTRA, Greece

Evangelia Apostolou

General Consulting Ltd. ISTRA, Greece

Georgia Papavgeri

General Consulting Ltd. ISTRA, Greece

Zacharias Agioutantis

University of Kentucky, zach.agioutantis@uky.edu

Achilleas Tripolitsiotis

Technical University of Crete, Greece

Follow this and additional works at: https://uknowledge.uky.edu/mng_facpub

Part of the Mining Engineering Commons

Right click to open a feedback form in a new tab to let us know how this document benefits you.

\section{Repository Citation}

Steiakakis, Chrysanthos; Apostolou, Evangelia; Papavgeri, Georgia; Agioutantis, Zacharias; and Tripolitsiotis, Achilleas, "Quantitative Correlation of Rainfall and Earth Surface Displacements for Slope Stability Studies" (2015). Mining Engineering Faculty Publications. 1.

https://uknowledge.uky.edu/mng_facpub/1

This Article is brought to you for free and open access by the Mining Engineering at UKnowledge. It has been accepted for inclusion in Mining Engineering Faculty Publications by an authorized administrator of UKnowledge. For more information, please contact UKnowledge@lsv.uky.edu. 


\title{
Quantitative Correlation of Rainfall and Earth Surface Displacements for Slope Stability Studies
}

\author{
Digital Object Identifier (DOI) \\ http://dx.doi.org/10.1117/12.2193463
}

\section{Notes/Citation Information}

Published in Proceedings of SPIE, v. 9535, Third International Conference on Remote Sensing and Geoinformation of the Environment (RSCy2015), article 95350M, p. 95350M-1 through 95350M-10.

Copyright 2015 Society of Photo Optical Instrumentation Engineers. One print or electronic copy may be made for personal use only. Systematic reproduction and distribution, duplication of any material in this paper for a fee or for commercial purposes, or modification of the content of the paper are prohibited.

Chrysanthos Steiakakis, Zacharias Agioutantis, Evangelia Apostolou, Georgia Papavgeri and Achilleas Tripolitsiotis, "Quantitative correlation of rainfall and earth surface displacements for slope stability studies", Proceedings of SPIE 9535, Third International Conference on Remote Sensing and Geoinformation of the Environment (RSCy2015), 95350M (June 19, 2015).

http://dx.doi.org/10.1117/12.2193463

This article is available at UKnowledge: https://uknowledge.uky.edu/mng_facpub/1 


\title{
Quantitative correlation of rainfall and earth surface displacements for slope stability studies
}

\author{
Chrysanthos Steiakakis ${ }^{\mathrm{a}^{*}}$, Zacharias Agioutantis ${ }^{\mathrm{b}}$, Evangelia Apostolou ${ }^{\mathrm{c}}$, Georgia Papavgeri ${ }^{\mathrm{c}}$, \\ Achilleas Tripolitsiotis $^{\mathrm{d}}$ \\ ${ }^{a}$ General Consulting Ltd "ISTRIA", 6 Dimitressa str, Athens, Greece, Tel: +30-210-7218323; E- \\ mail: steiakakis.chrys@istria.gr \\ ${ }^{\mathrm{b}}$ University of Kentucky, Department of Mining Engineering, Lexington, Kentucky, USA, E-mail: \\ zach.agioutantis@uky.edu \\ ${ }^{\mathrm{c}}$ Technical University of Crete, School of Mineral Resources Engineering, Rock Mechanics \\ Laboratory, 73100 Chania, Greece, E-mail: elina.apostolou@gmail.com \\ ${ }^{\mathrm{d}}$ Technical University of Crete, School of Mineral Resources Engineering, Geodesy and Geomatics \\ Engineering Laboratory, 73100 Chania, Greece, E-mail: atripol@mred.tuc.gr
}

\begin{abstract}
It is common sense that the possibility of a rockfall increases after an intense rainfall and it is well documented that rainfalls accelerate earth surface displacements such as landslides and rockfalls. This qualitative correlation is highly affected by the geology and climate condition of the area under consideration.

The research project entitled "Development of an integrated system for rockfall identification in highways", funded by the Operational Program Competitiveness and Entrepreneurship (co-funded by the European Regional Development Fund (ERDF)) aims to develop an operational system for early warning of rockfalls that occur along transportation corridors. To accomplish this goal the influence and the time gap between triggering mechanisms and rockfall incidents is investigated.

In this work, previous studies towards quantitative correlation of rainfall magnitude and earth surface displacements are briefly presented. Based on these works, and taking into account that rockfall incidents, in the majority of Mediterranean countries, are not well-documented, data obtained by a slope stability monitoring network are used to quantitatively determine the magnitude of the rainfall that caused the slope's movement.
\end{abstract}

Keywords: slope stability, triggering mechanisms, correlation

\section{INTRODUCTION}

Landslides, rockfalls and changes in slope stability are highly affected by the hydrology of the slope. Rainfall infiltration is a critical process that controls changes in slope hydrology and is significantly influenced by the soil properties, geology and climate. The infiltration increases saturation and causes fluid flow, threatening slope stability. Slope stability analyses based on the limit equilibrium methods cannot simulate this combined effect of rainfall properly, according to Borja, 2009 [1]. Nevertheless, an alternative analysis approach based on continuum modeling is presented by Borja, 2009 [1] that appears more suitable to simulate landslide and debris flow initiation in initially unsaturated slopes.

Some of the mechanisms and environmental factors that induce slope instability due to rainfall infiltration in shallow soils are: the increase of pore water pressure due to infiltration from the surface, the rise of the water table, the seepage forces, the contraction in loose soils which increases the pore pressure and leading to liquefaction, the rapid drainage of water and the erosion along pipeflow [2]. All the above mechanisms of slope instability are influenced by rainfall intensity.

Third International Conference on Remote Sensing and Geoinformation of the Environment (RSCy2015),

edited by Diofantos G. Hadjimitsis, Kyriacos Themistocleous, Silas Michaelides, Giorgos Papadavid,

Proc. of SPIE Vol. 9535, 95350M - (c) 2015 SPIE · CCC code: 0277-786X/15/\$18 · doi: 10.1117/12.2193463

Proc. of SPIE Vol. 9535 95350M-1 
In order to predict such slope instability incidents, rainfall thresholds should be comprised in a landslide/rockfall early warning system. Two major types of rainfall thresholds can be established one from empirical observations and another from physical modeling. Empirical observations are based on statistical analysis and correlation between rainfalls and landslide events. Physical thresholds are based on hydrologic and stability models, which relate rainfalls with pore pressures and slope stability [3,4]. Several attempts have been made to generate relationships between the triggering factors of landslides and/or rockfall events, such as rainfall intensity and duration [5-7]. Comparison by many authors has shown that the threshold values vary in different climatic regions and geologic conditions [4].

In this paper, the influence of the rainfall magnitude affecting slope movement is evaluated based on data obtained by a slope monitoring network. Prism monitoring targets were installed on the slopes and movement measurements were recorded for one year period and critically evaluated. Rain data were collected from two different stations and their location in relation to the slope is also examined. The velocity of slope movement is correlated with the accuracy of the instrument used and the time gap between rain measurement data.

\section{CORRELATION BETWEEN PRECIPITATION AND SLOPE MOVEMENTS}

The Mavropigi mine is located in Northern Greece and is very important for the power supply of Greece. Due to the observed movement on the southwest slopes, with an average rate of movements (velocity) of $10-20 \mathrm{~mm} /$ day [8], prism monitoring targets have been installed in order to measure surface movements. Targets from two areas have been examined; the area of the "A" Conveyors on the south slopes and the area of the "B" Conveyors on the southwest slopes (Fig. 1). In this paper only the rain influence on the slope movement is evaluated. The slope instability mechanism was presented by Kavvadas et al. (2013) [8].

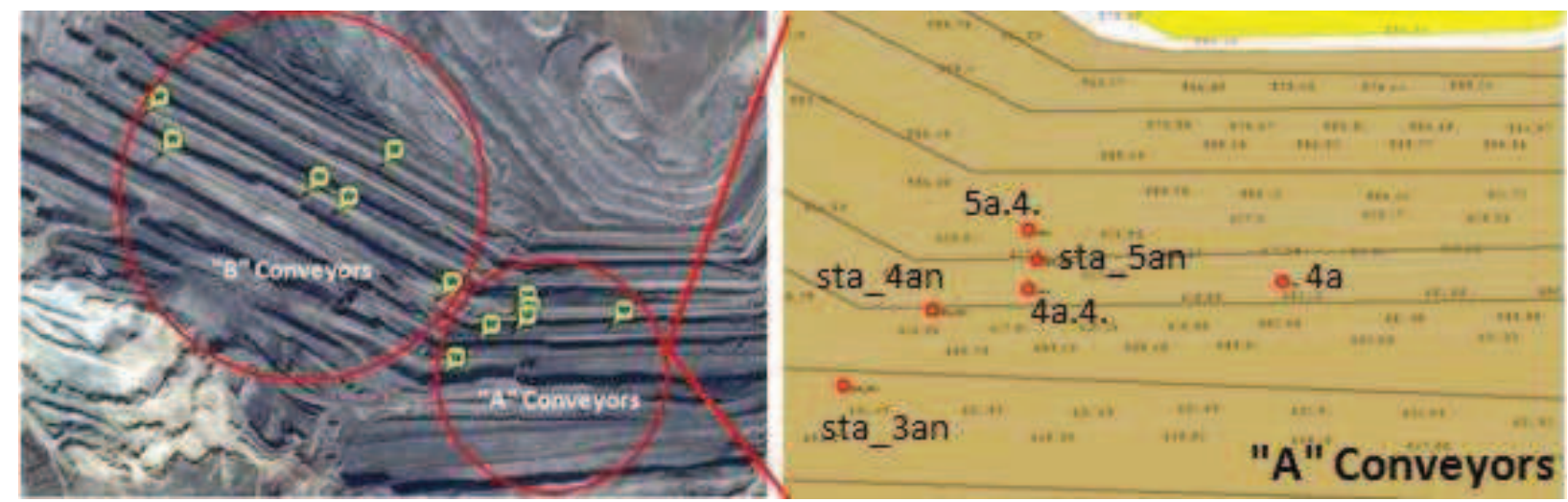

Figure 1. Location of the investigation areas and the prism targets in the area of the "A" Conveyors

The prism targets selected for the area of the "A" Conveyors are 4a, 4a.4., sta_3an, sta 4an, sta 5an, 5a.4. (Fig. 1) and their relative displacement against a stable point was measured using a robotic total station with an average time gap of 1-3 days. Figures 2 and 3 show vector displacements and velocity versus time according to these field measurements for the period between $01 / 04 / 2014$ to $16 / 01 / 2015$. In the same graphs precipitation is included for the same dates. 


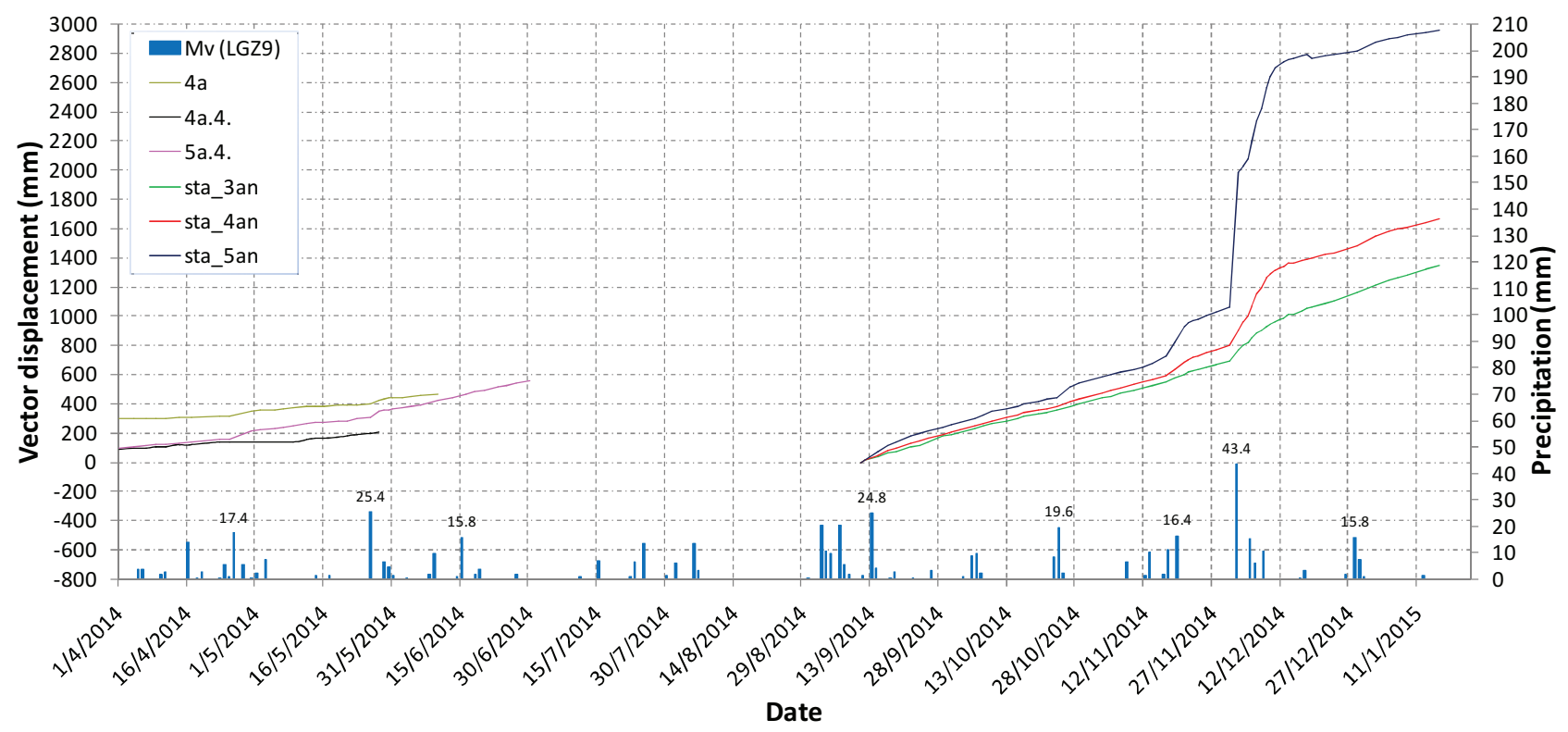

Figure 2. Vector displacement of prism targets in the area of the "A" Conveyors

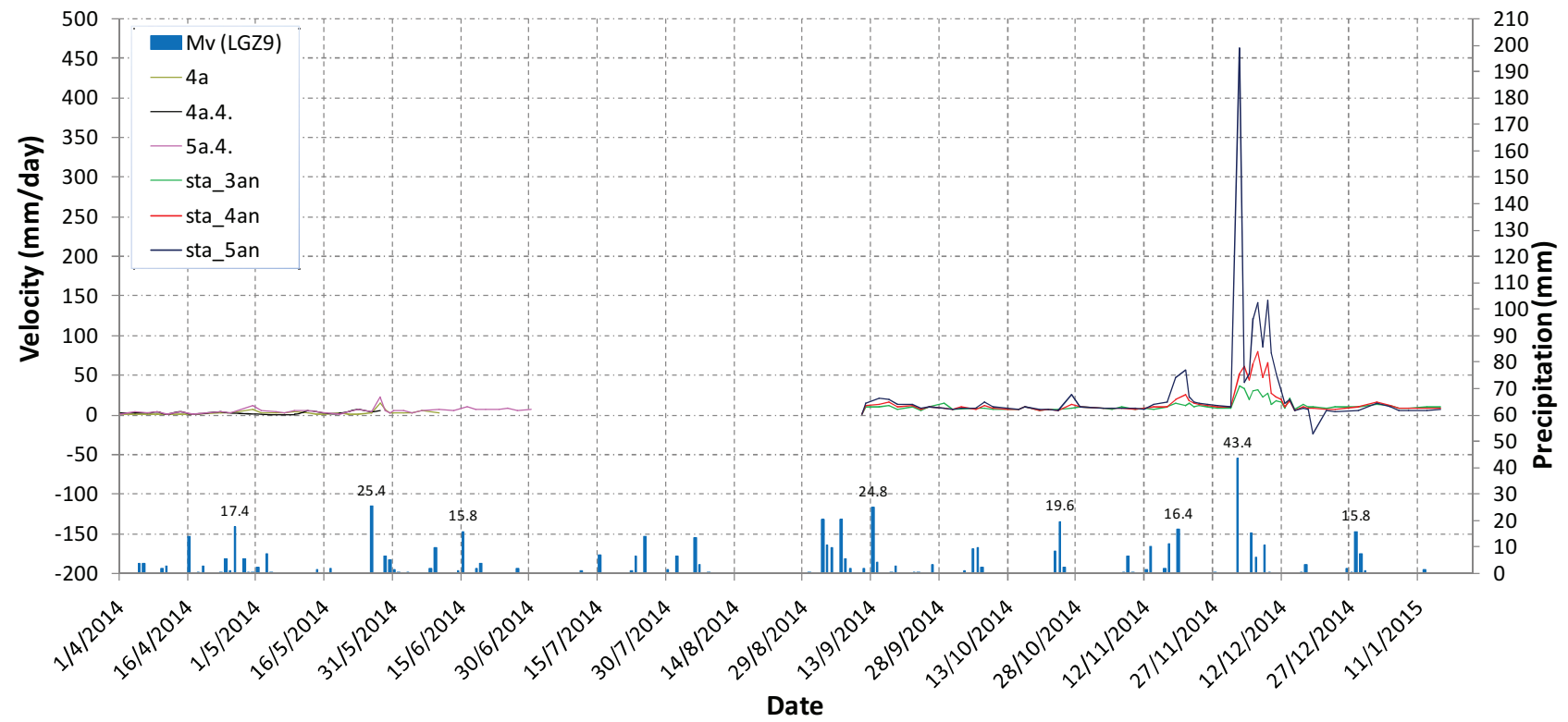

Figure 3. Velocity of prism targets in the area of the "A" Conveyors

Both Figures 2 and 3 clearly depict the qualitative correlation between displacement and the influence of the intense rainfalls. Moreover, several characteristic time periods can be observed and used for a quantitative determination of the critical rainfall threshold that accelerated earth surface displacements:

- On 26/05/2014 the precipitation was $25.4 \mathrm{~mm}$. The velocity of station $5 \mathrm{a} .4$. was $2.7 \mathrm{~mm} /$ day for the previous 105 days (from the date that monitoring was launched) prior to the rainfall and the vector displacement was 309 $\mathrm{mm}$. Two days after the rainfall the vector displacement increased to $353 \mathrm{~mm}$, corresponding to an average daily movement of $22.8 \mathrm{~mm} /$ day. For the following 33 days (until the date that monitoring of this particular 
target was completed) the vector displacement recorded was $560 \mathrm{~mm}$ and the average daily movement decreased to $5.9 \mathrm{~mm} /$ day.

- On 13/09/2014 the recorded precipitation was $24.8 \mathrm{~mm}$. Monitoring for the sta 5 an target was launched 2 days before the rainfall event on $11 / 09$ and on $12 / 09$ the velocity was $13.9 \mathrm{~mm} /$ day. Two days after the rainfall event the vector displacement reached $75.1 \mathrm{~mm}$ and the mean daily movement increased to $20.4 \mathrm{~mm} / \mathrm{day}$ and remained high during the following 2 days. Then, the mean daily movement decreased to $9 \mathrm{~mm} /$ day for 35 days and the vector displacement reached a total value of $443 \mathrm{~mm}$.

- On $02 / 12 / 2014$, the recorded precipitation was $43.4 \mathrm{~mm}$. The sta_5an target had a mean daily movement 14.3 $\mathrm{mm} /$ day for the previous 9 days and the vector displacement recorded was $1058 \mathrm{~mm}$. The day after the rainfall a significant rise on vector displacement is observed with a velocity of $462 \mathrm{~mm} /$ day and a vector displacement of $1982 \mathrm{~mm}$. Velocity remains high for the next 8 days and equal to $89 \mathrm{~mm} /$ day. Then, for 36 days, until the date that monitoring was completed on $16 / 01 / 2015$, the average velocity decreases to $7.6 \mathrm{~mm} /$ day and the vector displacement is $2961 \mathrm{~mm}$.

Comparing either the displacements or the velocities with the precipitation values, a significant increase of movement is observed when precipitation above $15 \mathrm{~mm}$ is recorded, while this impact is accelerated when daily precipitation exceeds $40 \mathrm{~mm}$. The highest vector displacement is $2961 \mathrm{~mm}$ in 127 days (i.e., 11.09.2014-16.01.2015) at the sta_5an target and the mean daily movement for the target ranges from 8 to $14 \mathrm{~mm}$ /day before and after the heavy rainfall event, whereas during the rainfall period an average velocity of $89 \mathrm{~mm} /$ day is observed.

Based on the present evaluation, a direct interaction between precipitation and daily movement is observed. Every intense rainfall event $(>15 \mathrm{~mm})$ is accompanied by an abrupt increase in the rate of movements. A characteristic example is the change in the rate after 02/12/2014. From the evaluation of all displacements, a time lag of $1-2$ days is detected in the response of slope movement to the intense rainfall events.

Furthermore, the time-dependent deformation behavior is in accordance with the findings presented by Zavodni, 2000 [9]. More specifically, and as presented previously in this Section, the general behavior of prism targets is regressive meaning that while displacements increase due to external disturbing factors such as rainfall they decelerate as soon as the factors are removed and tend to return to normal conditions. This type of movement favors the overall slope stability despite the ongoing displacements. In cases, though, of a prolonged effect of external factors (displacements) it is possible to overcome a critical threshold that may lead to a further generalized instability.

The following two sections aim to evaluate the impact that the location of meteorological stations, the instrumental errors and the frequency of measurements used for this analysis have on the overall analysis.

\section{EFFECT OF THE LOCATION OF THE WEATHER STATIONS}

Figure 4 shows the location of the two nearest weather stations to the Mavropigi mine. The first station is located $9 \mathrm{~km}$ northwest of the mine in the town of Ptolemais (Pt-LG26) and the second is $1 \mathrm{~km}$ east of the Mavropigi mine (MvLGZ9). The Mavropigi station provides data since April, 2014. For displacements prior to April 2014, precipitation data from the Ptolemais station have been used. In order to check the reliability of each weather station their daily precipitation records are plotted and presented in Figure 5.

As can be seen from Figure 5, there are dates where high precipitation is recorded in one station while significantly lower values are recorded in the other station, e.g. the precipitation values on 02/09/2014. On that date the Ptolemais station recorded $41.6 \mathrm{~mm}$, while the Mavropigi station recorded almost 50\% lower precipitation with $20.4 \mathrm{~mm}$ of rain. Furthermore, there are dates where no data are available on the Ptolemais station, e.g. on 02/12/2014, whereas the Mavropigi station recorded a high precipitation of $43.4 \mathrm{~mm}$. Therefore, a significant variation in the precipitation data from different stations is observed (Fig. 6). 


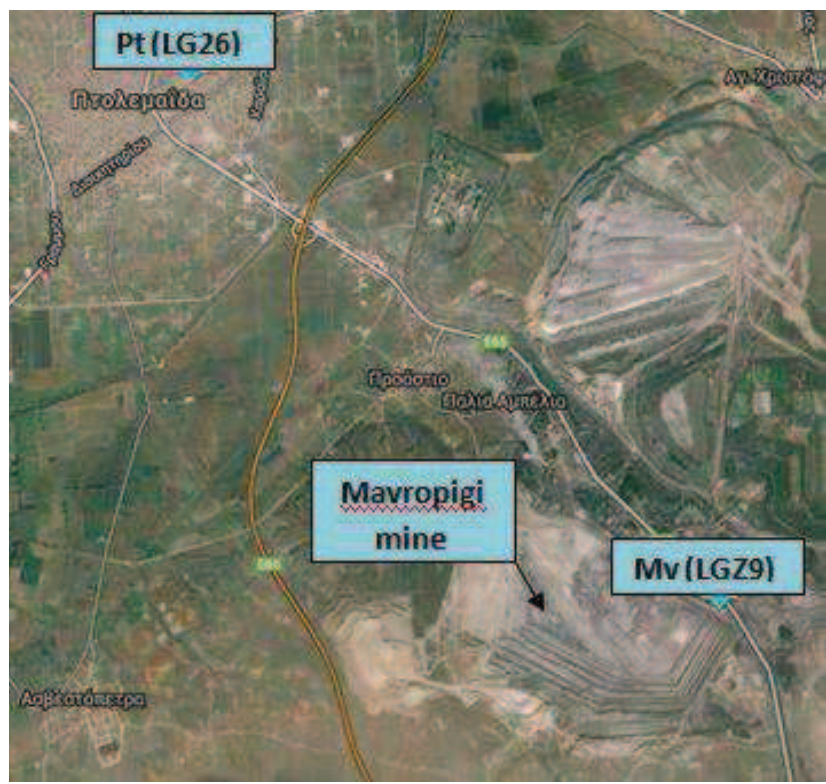

Figure 4. Location of the two weather stations used in this study with respect to the Mavropigi mine.

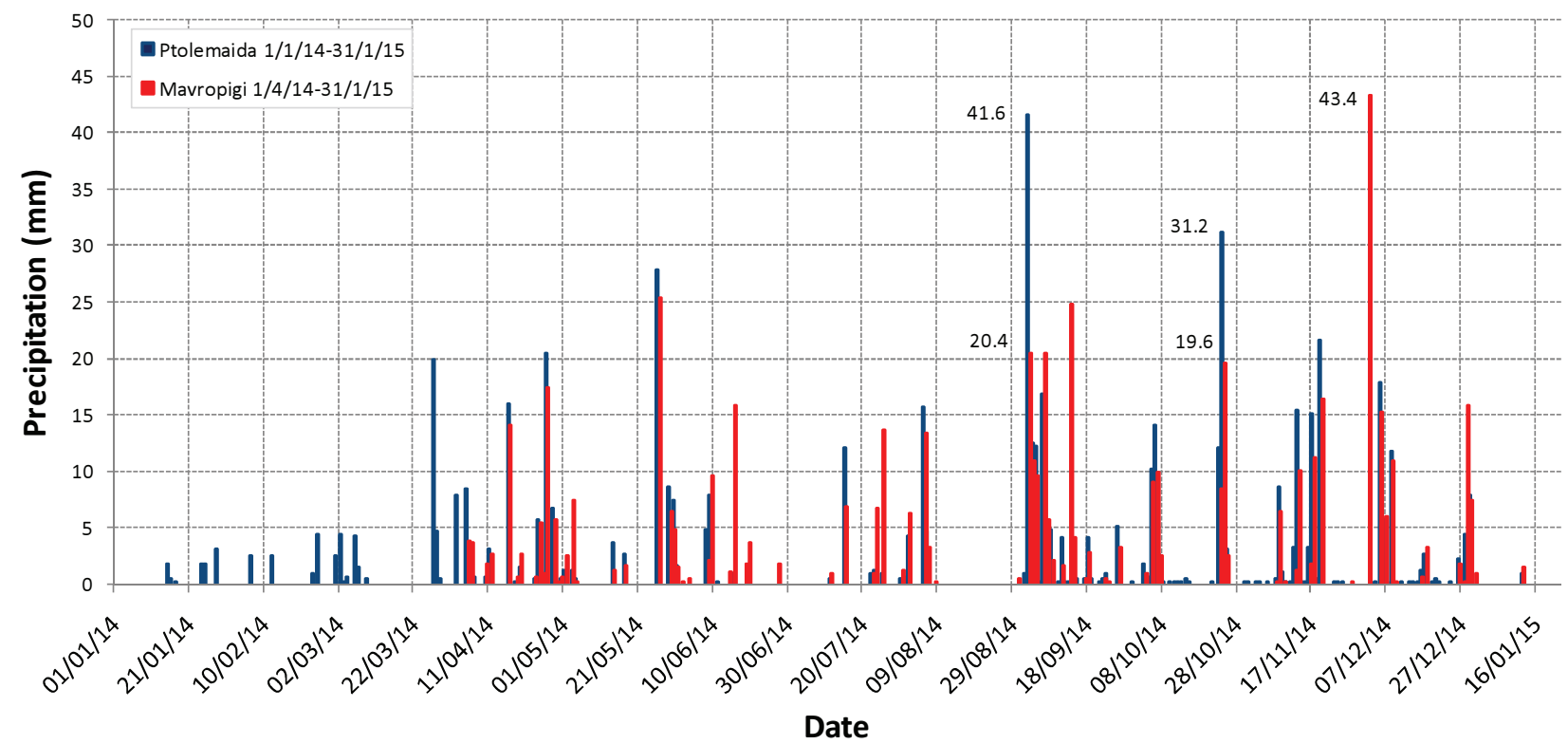

Figure 5. Precipitation versus time from two weather stations

It is very important that rainfall values are recorded close to the study area, because local climatic conditions can produce significantly different rainfall conditions. Consequently, for this study, the evaluation of displacements should not be unconditional, but should also consider other factors that relate to local conditions, such as the implementation of the exploitation plan at the mine. In periods where large movements are observed, mine operations are appropriately modified to either counteract such movements or avoid mobilized areas. 


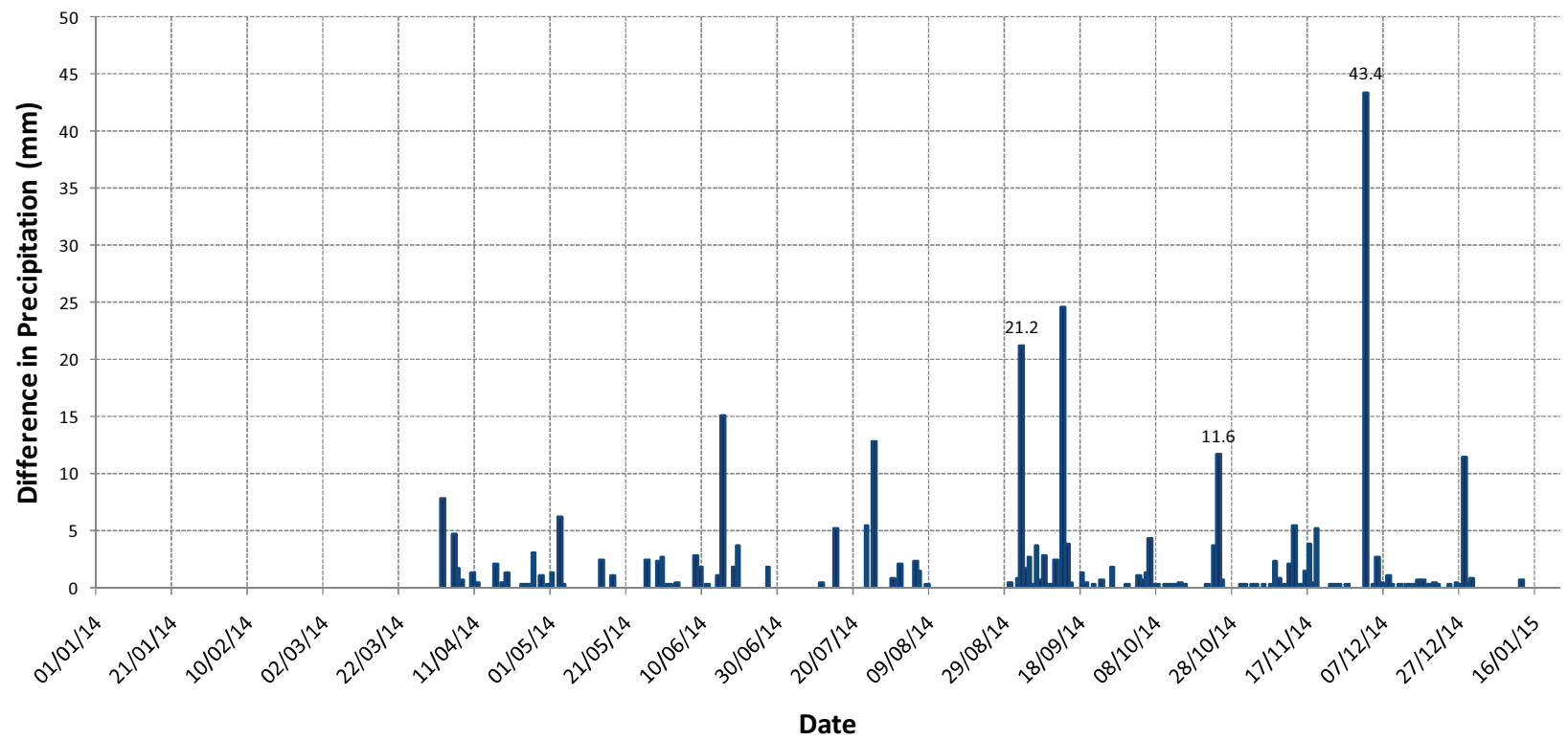

Figure 6. Difference in the precipitation data recorded by two weather stations

\section{INSTRUMENT ACCURACY AND FREQUENCY OF MEASUREMENTS}

Another important outcome from the evaluation of the available measurements are the negative values of velocity shown in the graph of velocity versus time (Fig. 3,8). In order to investigate this effect, measurements obtained by prism targets located at the area of the "B" Conveyors were further analyzed. More specifically, targets 5b,5b.2, stb_5b3,6neo, stb_6n and $8 \mathrm{~b}$ (Fig. 7) were chosen as they include measurements in the period being studied.

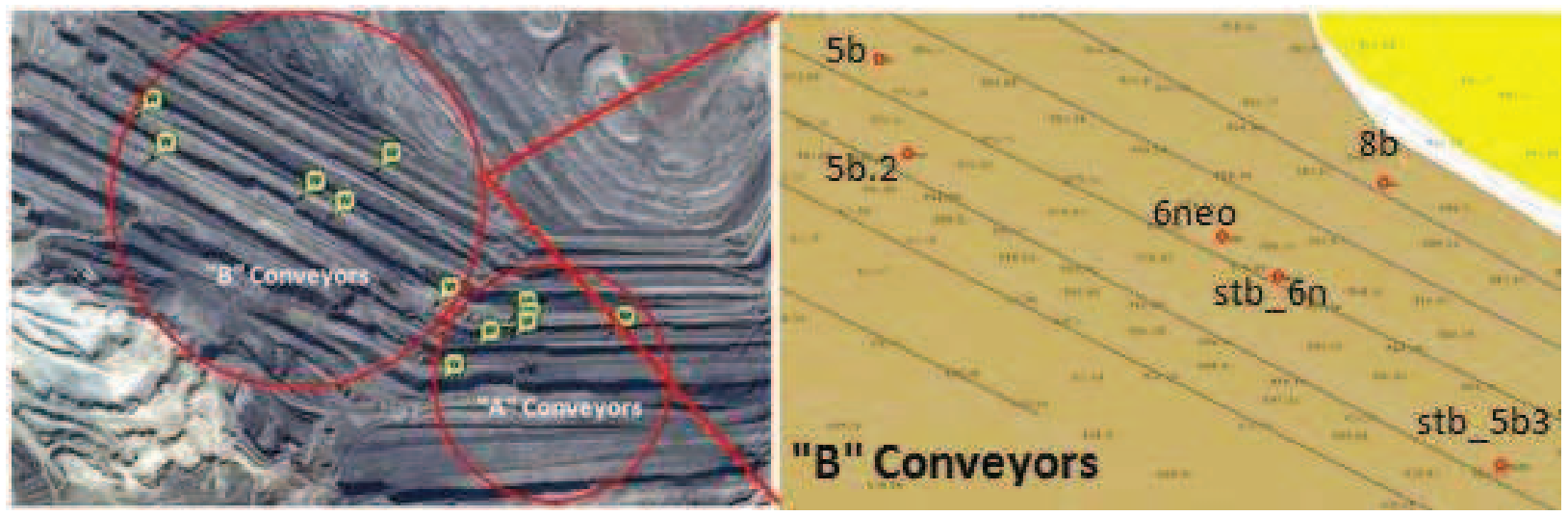

Figure 7. Location of prism targets in the area of the "B" Conveyors

Figure 8 presents velocity versus time for measurements taken over a period of $1-5$ days. The negative velocity values is a strong indicator of measurement accuracy since the slope is only moving forward and it only represents the measurement difficulties in vector displacement when movements are quite small. More specifically, for very short time intervals between measurements (i.e., 1 day), and when the recorded movements are small, aggregate vector displacement curves show that the slope moves "forward" and "backward", which is not feasible (Fig. 9). This "apparent" movement is due to the accuracy of the total station in the measurement of angles, which affects the calculated position of the prism target and, therefore, the magnitude of the aggregate displacement vector. 


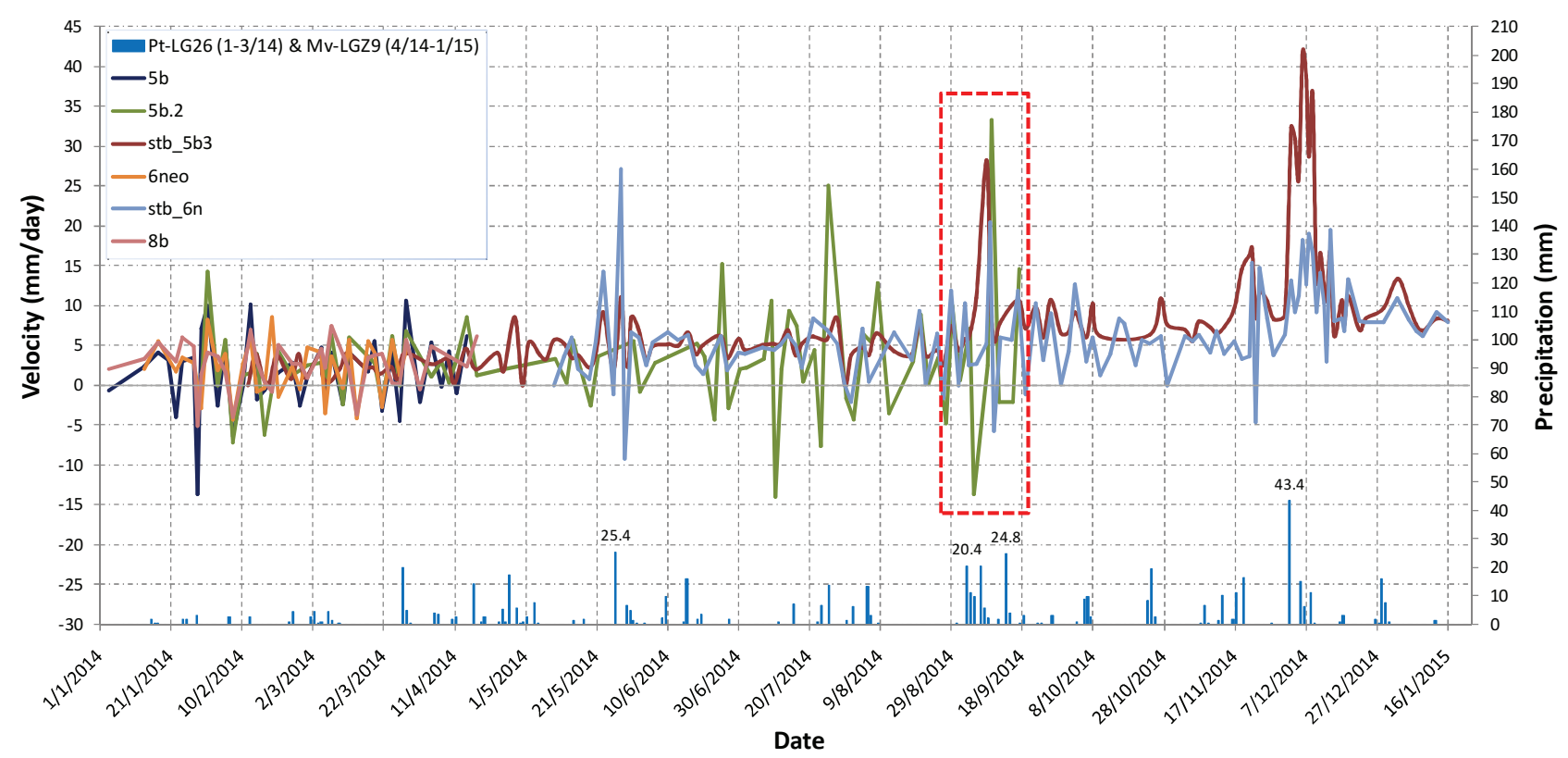

Figure 8. Velocity (rate of movement) versus time for a time-lag 1-5 days
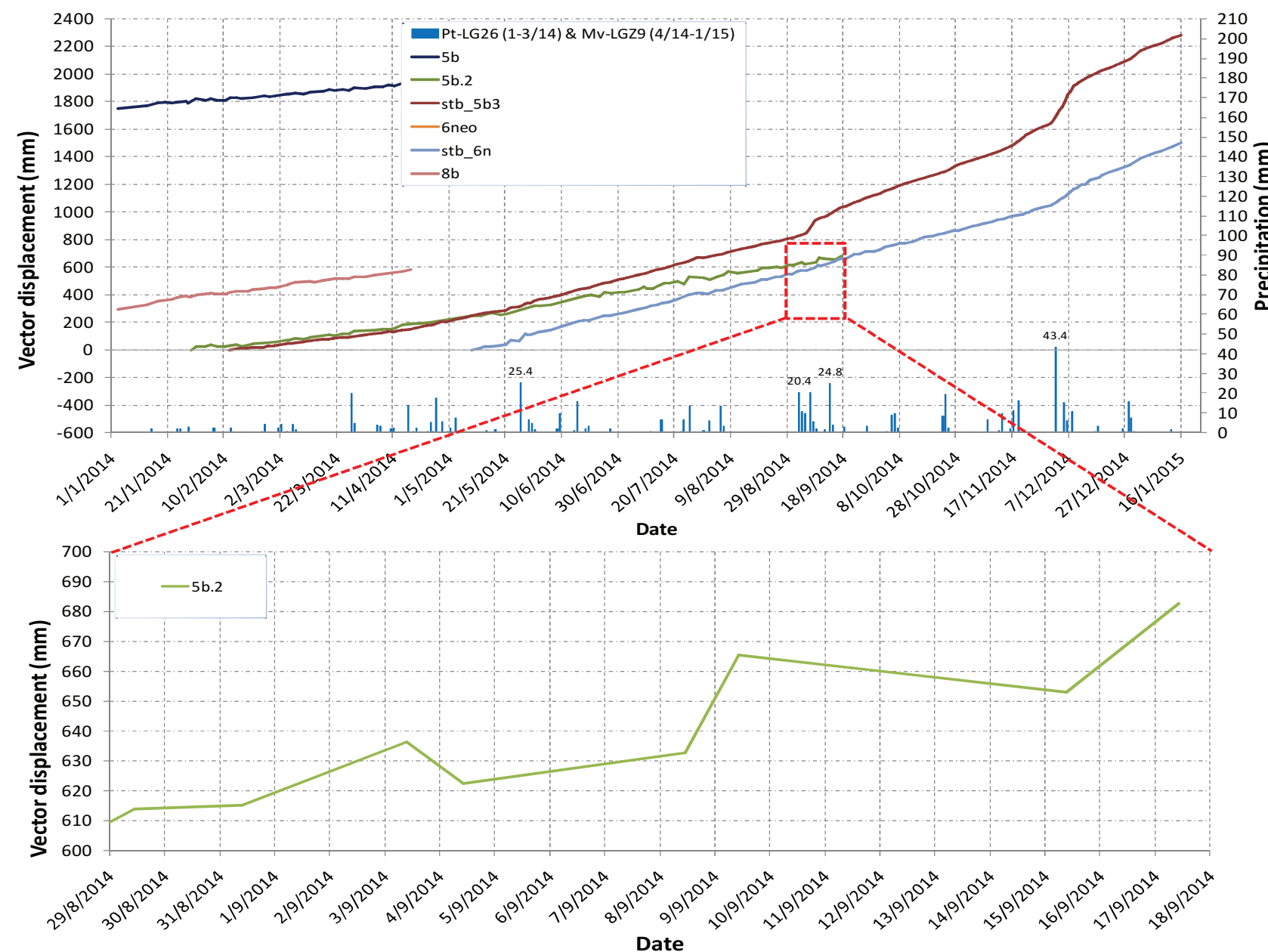

Figure 9. Vector displacement of prism targets in the area of the "B" Conveyors 
The positive and negative velocity values that are calculated and plotted, are only present in cases of small daily movements, i.e. $<10 \mathrm{~mm}$. When the magnitude of movements increase above this value or the frequency of measurements decreases to more than a couple of days, negative velocity values do not appear and a smoother displacement vector curve is generated.

A high accuracy $(0.5 \mathrm{cc})$ total station was used to measure movement vectors, but even with the higher accuracy instrument, vector displacements measured in locations with no movement or very small movement, again may result in a positive or negative change in velocity calculations. A reduction in such errors for very small displacements, which is not the case for most of the measurements in this study, can be accomplished by calculating only the direct distance between observation station and target prism; under such conditions the angular measurement errors are eliminated.

In order to verify the effect of measurement frequency in the fluctuation of velocity, fewer measurements were selected for each of the above targets to create the same graph, so that the time gap between measurements is increased to $5-10$ days. Results are shown in Figure 10, where a smooth change in velocity is observed that takes only positive values. This outcome shows that errors are reduced so that measurements are more reliable. For example, regarding the $5 \mathrm{~b} .2$ target (green line in Figures 8 and 10), there are 11 measurements for the period between 25/08/2014 - 17/09/2014 (i.e., red rectangle in Figure 8) and the time gap between them is $1-4$ days, with a fluctuation of velocity that ranges from 33 $\mathrm{mm} /$ day to $-14 \mathrm{~mm} /$ day. Comparatively for the same period (i.e., red rectangle in Figure 10), the number of records decreases to 4 and the time gap increases to 6 - 9 days, with a mean movement rate of $4 \mathrm{~mm} /$ day. The velocity (rate) is calculated based on the time interval of the measurements so in the latter case the velocity curve appears smoother.

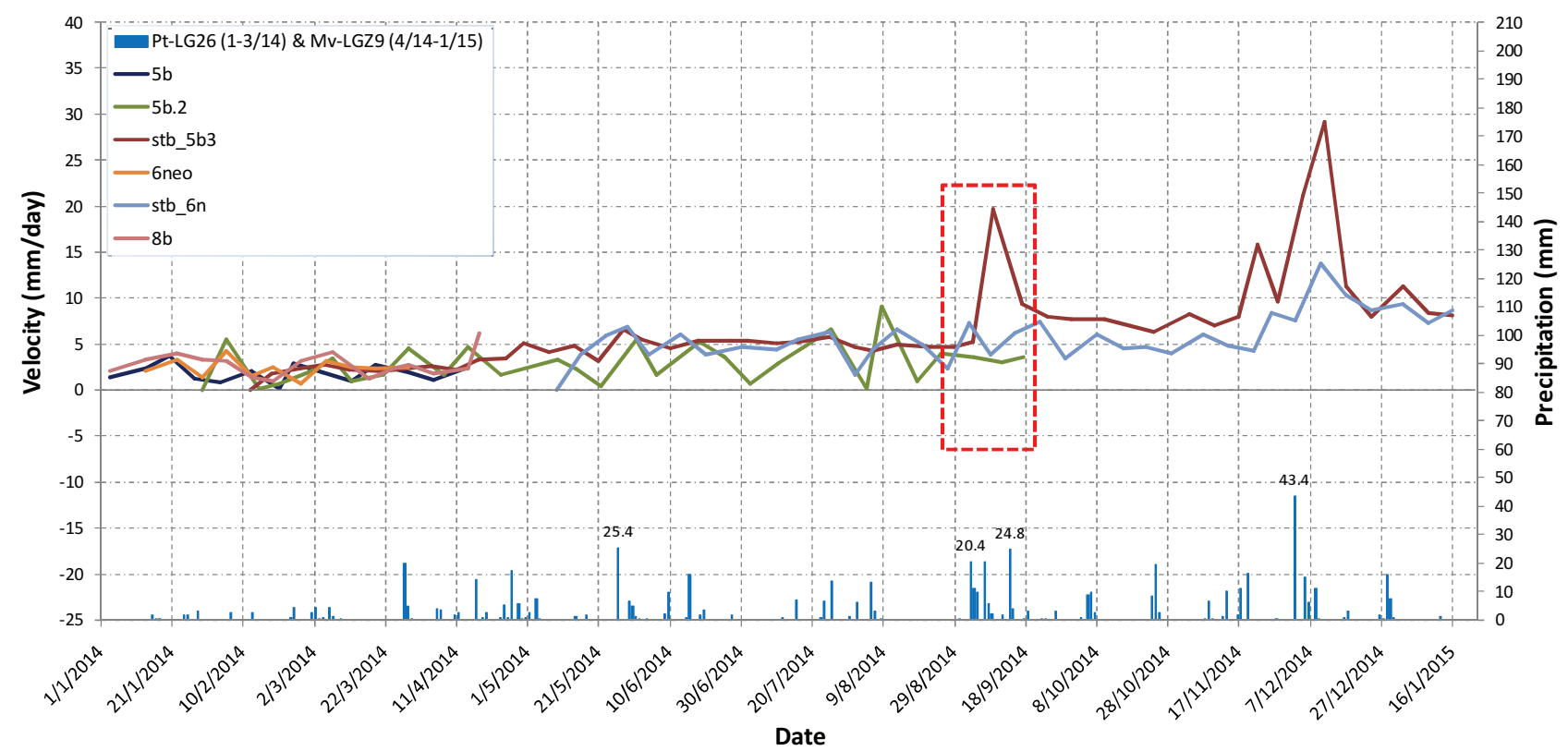

Figure 10. Velocity (rate of movement) versus time for a time-lag 5-10 days

\section{CONCLUSIONS}

Slope movements at a lignite open-pit mine in relation to rainfall records and survey measurements have been evaluated and presented. For the period between 01/2014-01/2015 the slopes were moving with an average velocity of about 5-10 $\mathrm{mm} /$ day.

It was found that there is a strong correlation between precipitation and daily movement for the areas of south and southwest slopes of the Mavropigi mine. The maximum daily movement after intense rainfall is usually observed with a time-lag of 1-2 days and remains high for a period of 3-8 days. For a daily precipitation less than $15 \mathrm{~mm}$, negligible values of daily movement is observed and a movement rate of about $15 \mathrm{~mm} /$ day was observed. For a daily rainfall value between 15 and $40 \mathrm{~mm}$ the maximum movement rate ranges from $20-25 \mathrm{~mm} /$ day. For precipitation values higher than 
$40 \mathrm{~mm}$, the mean daily movement increases to $50-150 \mathrm{~mm} /$ day during the 8 days following intense rainfall in the area of the "A" conveyors and to $20-40 \mathrm{~mm} /$ day during the 7 days following the rainfall event at the southwest slopes, where the "B" conveyors are installed.

The location of the weather station used to obtain precipitation data is directly related to the quality of the correlation between rainfall and slope movements. When the weather station is close to the study area the correlation between displacements and precipitation is more reliable. In cases where no data are available from a weather station near the study area, correlation results may be inaccurate. In addition, the role of mining operations should also be included in the evaluation of slope movements.

Furthermore, it has been observed that for daily movements lower than $10 \mathrm{~mm} /$ day, calculated rates may not be accurate due to low accuracy in measured displacements. Such inaccuracies can be reduced by increasing the time interval used to calculate movement rate values. Obviously, movement values used as thresholds are directly related to the accuracy of the surveying instrument(s).

Finally, the area of the south slopes of the Mavropigi mine shows a regressive type of movement, which is steady and higher in the area of the "A" conveyors. Daily movements decelerate and return to a constant average rate after external factors, such as precipitation or the increase of the inclination, are removed. This behavior is beneficial to the operation of the mine, since the observed increase of movements is associated to external events which can either be controlled (reduction of the inclination, discharge) or just end (e.g., heavy rainfall). In any case, the measured data must be analyzed in conjunction with the external factors and appropriate remediation methods or precautions measures should be selected.

\section{ACKNOWLEDGMENTS}

This work has been performed under the framework of the "Cooperation 2011" project ISTRIA (11_SYN_9_1389) funded from the Operational Program "Competitiveness and Entrepreneurship" (co-funded by the European Regional Development Fund (ERDF)) and managed by the Greek General Secretariat for Research and Technology.

\section{REFERENCES}

[1] Borja R. I., "Landslides and Debris Flow Induced by Rainfall", Insights, Institute of Advanced Study, Durham University, Volume 2, Number 3 (2009)

[2] Crosta G. B., Agliardi F., Frattini P., Sosio R., "Landslide triggering mechanisms in Europe - Overview and State of the Art Work Package 1.1 - Identification of mechanisms and triggers", NGI, SafeLand - FP7, Rev. No: $2,84-88(2012)$

[3] Aleotti, P., " A warning system for rainfall-induced shallow failures", Engineering Geology 73, 247-265 (2004)

[4] Dahal R. K., Hasegawa S., "Representative rainfall thresholds for landslides in the Nepal Himalaya", Geomorphology 100, $429-443(2008)$

[5] Krautblatter, $\mathrm{M}$ and Moser, M., "A non-linear model coupling rockfall and rainfall intensity based on a four year measurement in a high Alpine rock wall (Reintal, German Alps)", Nat. Hazards Earth Syst. Sci., 9, 1425$1432(2009)$

[6] Absari, M.K., Ahmed, M., Rajesh Singh T.N., Ghalayani, I., "Rainfall, A major cause for rockfall hazard along the roadways, highways, and railways on hilly terrains in India", Engineering Geology for Society and Territory, Vol. 1, 457-460 (2015).

[7] Delonca, A., Gunzburger, Verdel, T., "Statistical correlation between meteorological and rockfall databases", Nat. Hazards Earth Syst. Sci., 14, 953-1964 (2014)

[8] Kavvadas M., Agioutantis Z., Schilizzi P., Steiakakis C., " Stability and movements of open-pit lignite mine in Northern Greece", ICSMGE, 2193-2196 (2013)

[9] Zavodni, Z. M., 2000, "Time-Dependent Movements of Open-Pit Slopes", Chapter 8, Slope stability in surface mining, Hustrulid, McCarter, Vanzyl (eds), Society for Mining Metallurgy and Exploration 
[10] Tommasi P., Pellegrini P., Boldini D., Ribacchi R., "Influence of rainfall regime on hydraulic conditions and movement rates in the overconsolidated clayey slope of the Orvieto hill (central Italy)", Can. Geotech. J. 43: 70-86 (2006)

[11] Kayabasi A., Gokceoglu C., "Coal mining under difficult geological conditions: The Can lignite open pit (Canakkale, Turkey), Engineering Geology 135-136 (2012) 